\title{
Speciation Studies of Some Metal Complexes with L-Aspartyl-L-phenylalanine Methyl Ester by Potentiometry
}

\author{
Makoto Alhara*†, Fudeko Tanaka*, Minori Fujimoto* and Kô TaKehara** \\ *Faculty of Home Life Science, Fukuoka Women's University, \\ Kasumigaoka, Fukuoka 813, Japan \\ **College of General Education, Kyushu University, Ropponmatsu, Fukuoka 810, Japan
}

\begin{abstract}
The stoichiometry and stability constants of the complexes formed between nickel(II), cobalt(II), copper(II) and manganese(II) with L-aspartyl-L-phenylalanine methyl ester (aspartame, LH) have been determined potentiometrically at $25^{\circ} \mathrm{C}$ and $\mu=0.1$. Nickel(II) and cobalt(II) react with aspartame to form $M L_{,}, M_{2}$ and $M_{3}$ type complexes. Copper(II) forms $\mathrm{ML}$ and $\mathrm{ML}_{2}$ type complexes. On the other hand, manganese(II) forms $\mathrm{ML}$ type complexes. The Irving-Williams' order, $\mathrm{Co}(\mathrm{II})<\mathrm{Ni}(\mathrm{II})<\mathrm{Cu}(\mathrm{II})$, was found to be satisfied for $\mathrm{ML}^{+}$complexes. Complex distribution depending on $\mathrm{pH}$ and metal/aspartame ratio is given for these systems.
\end{abstract}

Keywords Stability constant, metal complex, L-aspartyl-L-phenylalanine methyl ester

L-Aspartyl-L-phenylalanine methyl ester (aspartame) is used as a low-calorie sweetener and has been approved as a food additive. ${ }^{1}$ A number of methods have been reported for the determination of aspartame by highperformance liquid chromatography ${ }^{2,3}$, thin-layer chromatography 4 and capillary isotachophoresis. ${ }^{5}$ Aspartame has a limited stability in aqueous systems ${ }^{1}$ and its stability has been investigated.6,7 Aspartame is hydrolyzed at $\mathrm{pH}>9$ and the presence of zinc(II) seems to stabilize the system. ${ }^{8}$

The copper(II)- and zinc(II)-aspartame complexes have been chosen as the reverse phase chromatographic resolution agents of amino acid enantiomers. ${ }^{9}$ Electrokinetic resolution of amino acid enantiomers with copper(II)-aspartame supporting electrolyte has also been reported. ${ }^{10}$ The resolution is based on the formation of a ternary metal(II)-amino acid-aspartame complex.

Clarifying the stoichiometry and stability constants of metal complexes with aspartame is important for chemical analyses and chemical reactions of aspartame. The equilibrium studies of aspartame with metal ions have not been carried out so extensively as those of other dipeptides. The complex formed by zinc(II) ion with aspartame has been investigated and the stability constants were reported. ${ }^{11}$

This paper deals with the stoichiometry and stability constants of nickel(II), cobalt(II), copper(II) and manganese(II) complexes with aspartame. These studies have been performed by potentiometry. The dependence of the complex species on $\mathrm{pH}$ and metal/

† To whom correspondence should be addressed. aspartame ratio has been investigated.

\section{Experimental}

\section{Reagents}

Each solution was prepared from metal chloride. Each concentration was determined by direct EDTA titration using appropriate indicators. The peptide, Laspartyl-L-phenylalanine methyl ester, was purchased from Ajinomoto Co. Japan and used without purification. The concentration of aspartame was determined by potentiometric titration. All other chemicals were reagent grade. Water was distilled and deionized.

\section{Measurements}

The solutions of $1: 1,1: 2,1: 3,2: 3$ and $2: 5$ metal to aspartame ratio were titrated with potassium hydroxide solution under nitrogen at $25.0 \pm 0.1^{\circ} \mathrm{C}$. The concentrations of metal ions were $1.00 \times 10^{-3} \mathrm{~mol} \mathrm{dm}^{-3}$. Ionic strength was adjusted to 0.1 with potassium chloride.

For $\mathrm{pH}$ measurements, a Hitachi F8 digital $\mathrm{pH}$ meter was used. The $\mathrm{pH}$ meter was calibrated in terms of hydrogen-ion concentration. The accuracy of the $\mathrm{pH}$ meter was $\pm 0.001 \mathrm{pH}$ unit. The dissociation constants of aspartame were calculated from titration data in the absence of metal ions.

\section{Results and Discussion}

Acid dissociation constants of aspartame and stability constants of its metal complexes

Acid dissociation of aspartame falls into two groups, 
protonated amino and carboxyl groups, as follows:

$$
\mathrm{LH}_{2}{ }^{+}=\mathrm{LH}+\mathrm{H}^{+}
$$

and

$$
\mathrm{LH}=\mathrm{L}^{-}+\mathrm{H}^{+} .
$$

The acid dissociation constants $\left(K_{1}\right.$ and $\left.K_{2}\right)$ are written as

$$
\begin{aligned}
& K_{1}=\frac{[\mathrm{LH}]\left[\mathrm{H}^{+}\right]}{\left[\mathrm{LH}_{2}^{+}\right]} \\
& K_{2}=\frac{\left[\mathrm{L}^{-}\right]\left[\mathrm{H}^{+}\right]}{[\mathrm{LH}]}
\end{aligned}
$$

where $\mathrm{LH}$ is aspartame.

The value of $K_{1}$ and $K_{2}$ were calculated from the titration data of aspartame, using the computer program PKAS. ${ }^{12}$ The values of $\log K_{1}$ and $\log K_{2}$ were $3.16 \pm 0.04$ and $7.71 \pm 0.03$ at $25^{\circ} \mathrm{C}$, respectively. Our results were almost identical with those of the literature $\left(\mathrm{p} K_{1}=3.18\right.$ and $\mathrm{p} K_{2}=7.82$ at $20^{\circ} \mathrm{C}$ ). ${ }^{5}$

Complex systems were studied in the presence of the divalent metal ions within the limits of hydrolysis and solubilities. Stability constants of the metal complexes were calculated with the program, SCOGS2 (Stability Constants of General Species 2). ${ }^{12}$ This is a general computer program that accepts data from $\mathrm{pH}$ titration to refine a set of estimated stability constants.

The complex formation between the species, metal ion (M), aspartame ( $\mathrm{LH}$ ) and proton $(\mathrm{H})$ can be represented by the following reaction:

$$
m \mathbf{M}+l \mathbf{L}+h \mathrm{H}=\mathbf{M}_{m} \mathbf{L}_{l} \mathrm{H}_{h} .
$$

The stability constant for the above reaction is as follows:

$$
\beta_{m l h}=\frac{\left[\mathrm{M}_{m} \mathrm{~L}_{l} \mathrm{H}_{h}\right]}{[\mathrm{M}]^{m}[\mathrm{~L}]^{l}[\mathrm{H}]^{h}}
$$

where $[\mathrm{M}],[\mathrm{L}]$ and $[\mathrm{H}]$ are the concentrations of free metal ion, ligand and hydrogen ion, respectively.

The following sets of equations define the total system:

$$
\begin{aligned}
& C_{\mathrm{M}}=[\mathrm{M}]+\sum m \beta_{m l h}[\mathrm{M}]^{m}[\mathrm{~L}]^{l}[\mathrm{H}]^{h} \\
& C_{\mathrm{L}}=[\mathrm{L}]+\sum l \beta_{m l h}[\mathrm{M}]^{m}[\mathrm{~L}]^{l}[\mathrm{H}]^{h} \\
& C_{\mathrm{H}}=[\mathrm{H}]+\sum h \beta_{m l h}[\mathrm{M}]^{m}[\mathrm{~L}]^{l}[\mathrm{H}]^{h} .
\end{aligned}
$$

For each set of constants, the metal ion and ligand concentrations are those that fulfil

$$
C_{\text {total calculated }}=C_{\text {total experimental. }}
$$

The desired result from calculations with SCOGS2 is to refine the stability constants so that the concentrations of metal ion and ligand calculated with the stability constants coincide with the experimental ones. The SCOGS2 allows for 10 titrations, a total of 200 readings and 24 species. Good fits of simulations for metal complex systems have been confirmed. ${ }^{12}$ The program used 6-8 titrations for each metal-aspartame system. Metal ion concentrations were varied over a two-fold range and the ligand concentrations were varied fivefold. Attempts were made to fit a large number of different models to the experimental data and to avoid coincident errors at the calculations.

Copper(II) forms $1: 1$ and $1: 2$ complexes with aliphatic peptides and nickel(II) forms $1: 1,1: 2$ and $1: 3$ complexes. ${ }^{13,14}$ Peptide protons are retained in the complexes. Other species are the complexes in which one or two peptide protons are dissociated. Therefore the models which we used for the simulations contained all theoretically possible species of $1: 1$ and $1: 2$ complexes for the copper(II) system and $1: 1,1: 2$ and $1: 3$ complexes for the nickel(II) and cobalt(II) systems. The model for the manganese(II) system contains two or three species since precipitation occurs at lower $\mathrm{pH}$ values.

A typical titration curve of solution containing nickel(II) ion and aspartame with a ratio of $1: 3$ is shown in Fig. 1. Including data for the nickel(II) system and taking all species into account, many models were investigated. The following model for the system leads to a very good simulation:

model 1: $\mathrm{NiL}^{+}, \mathrm{NiLH}_{-1}, \mathrm{NiL}_{2}, \mathrm{NiL}_{2} \mathrm{H}^{+}, \mathrm{NiL}_{2} \mathrm{H}_{2}{ }^{2+}$ and $\mathrm{NiL}_{3}{ }^{-}$.

The stability constants obtained with SCOGS2 program are listed in Table 1. From the stability constants, the titration curves were recalculated and compared with those obtained experimentally. A very good simulation of each titration curve was obtained. A typical calculated curve for $\mathrm{Ni}$ : aspartame $=1: 3$ is shown in Fig. 1.

The following models for cobalt(II), copper(II) and manganese(II) systems give very good simulations:

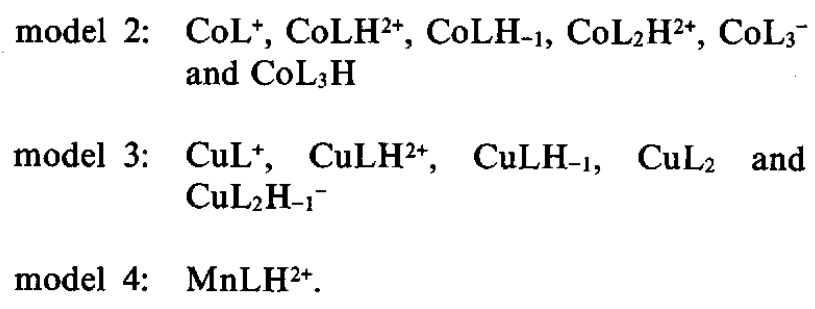
and $\mathrm{CoL}_{3} \mathrm{H}$

model 3: $\mathrm{CuL}^{+}, \mathrm{CuLH}^{2+}, \mathrm{CuLH}_{-1}, \mathrm{CuL}_{2}$ and $\mathrm{CuL}_{2} \mathrm{H}_{-1}^{-}$

model 4: $\mathrm{MnLH}^{2+}$.

The calculated curve of $1: 3$ system using these stability constants for cobalt(II) complexes is shown in Fig. 2. The model for the system leads to a very good result. The models for the copper(II) and manganese(II) systems showed good results.

The equilibria for these metal complexes involved in the above models are as follows: 
Table 1 Stability constants of metal complexes with aspartame in $0.1 \mathrm{~mol} \mathrm{dm}{ }^{-3} \mathrm{KCl}$ at $25^{\circ} \mathrm{C}$ (Standard deviations are shown in parentheses.)

\begin{tabular}{lrrrrr}
\hline \multirow{2}{*}{ mlh $)$} & \multicolumn{5}{c}{$\log \beta_{m l h}$} \\
\cline { 2 - 6 } & $\mathrm{Mn}(\mathrm{II})^{\mathrm{a}}$ & $\mathrm{Co}(\mathrm{II})^{\mathrm{a}}$ & $\mathrm{Ni}(\mathrm{II})^{\mathrm{a}}$ & \multicolumn{1}{c}{$\mathrm{Cu}(\mathrm{II})^{\mathrm{a}}$} & \multicolumn{1}{c}{$\mathrm{Zn}(\mathrm{II})^{\mathrm{b}}$} \\
\hline 111 & $10.15(0.03)$ & $10.50(0.01)$ & & $10.98(0.05)$ & $9.33(0.05)$ \\
110 & & $4.01(0.01)$ & $4.88(0.03)$ & $6.89(0.03)$ & $3.79(0.02)$ \\
$11-1$ & & $-4.93(0.05)$ & $-2.41(0.04)$ & $0.16(0.07)$ & $-4.76(0.31)$ \\
122 & & $20.79(0.01)$ & & \\
121 & $13.93(0.04)$ & $16.04(0.01)$ & & $13.21(0.15)$ \\
120 & & $9.69(0.01)$ & $12.18(0.06)$ & $6.87(0.07)$ \\
$12-1$ & & & $4.17(0.08)$ & \\
131 & & & & \\
130 & & & & & \\
\hline
\end{tabular}

a. Standard deviations for runs repeated 6-9 times: 0.01-0.02 for $\mathrm{Mn}(\mathrm{II}), 0.05-0.06$ for $\mathrm{Co}$ (II), $0.03-0.04$ for $\mathrm{Ni}(\mathrm{II}), 0.05-0.06$ for $\mathrm{Cu}(\mathrm{II})$ systems. b. Ref. $11, \mu=0.15,37^{\circ} \mathrm{C}$.

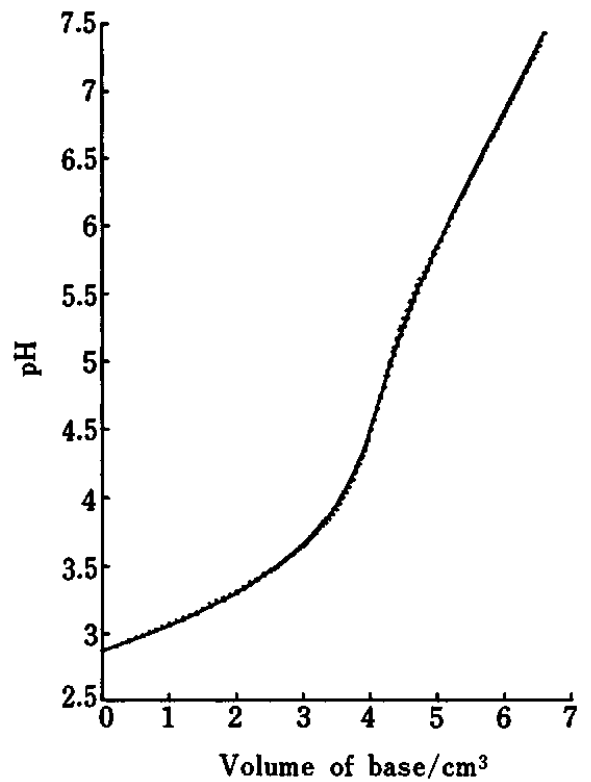

Fig. 1 Titration curves for $1: 3$ mixture of nickel(II) with aspartame. Nickel(II) concentration is $1.00 \times 10^{-3} \mathrm{~mol} \mathrm{dm}^{-3}$. Solid line represents the experimental titration curve, dotted line the calculated values.

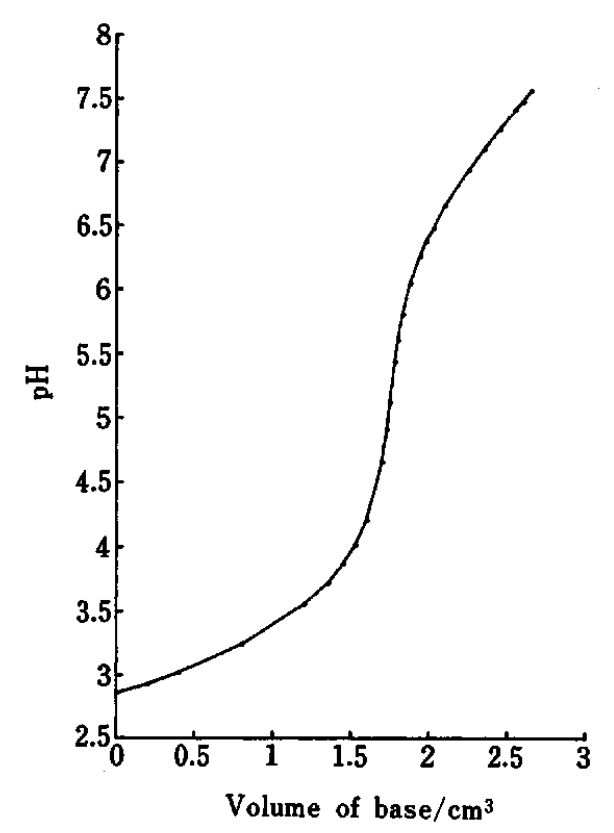

Fig. 2 Titration curves for $1: 3$ mixture of cobalt(II) with aspartame. Cobalt(II) concentration is $1.00 \times 10^{-3} \mathrm{~mol} \mathrm{dm}^{-3}$. Solid line represents the experimental titration curve, dotted line the calculated values.

$$
\begin{array}{ll}
\mathrm{M}^{2+}+\mathrm{L}^{-}=\mathrm{ML}^{+} & : 110 \\
\mathrm{M}^{2+}+\mathrm{L}^{-}+\mathrm{H}^{+}=\mathrm{MLH}^{2+} & : 111 \\
\mathrm{M}^{2+}+\mathrm{L}^{-}=\mathrm{MLH}_{-1}+\mathrm{H}^{+} & : 11-1 \\
\mathrm{M}^{2+}+2 \mathrm{~L}^{-}=\mathrm{ML}_{2} & : 120 \\
\mathrm{M}^{2+}+2 \mathrm{~L}^{-}+\mathrm{H}^{+}=\mathrm{ML}_{2} \mathrm{H}^{+} & : 121 \\
\mathrm{M}^{2+}+2 \mathrm{~L}^{-}+2 \mathrm{H}^{+}=\mathrm{ML}_{2} \mathrm{H}_{2}{ }^{2+} & : 122 \\
\mathrm{M}^{2+}+2 \mathrm{~L}^{-}=\mathrm{ML}_{2} \mathrm{H}_{-1}+\mathrm{H}^{+} & : 12-1
\end{array}
$$$$
\beta_{m l h}
$$

Species distribution depending on metal/ ligand ratio and $p H$

The concentrations of the complexes calculated with the stability constants in Table 1 are presented as plots of degree of formation $v s$. pH in Figs. 3-6.

Figures 3(a), (b) and (c) show the species distribution diagrams of $1: 1,1: 2$ and $1: 3 \mathrm{Ni}$ (II)-aspartame systems. It is found that the amount of nickel complexes increases with increasing aspartame concentration. Nickel(II) aqueous ion dominates at low $\mathrm{pH}$ region, as shown in 

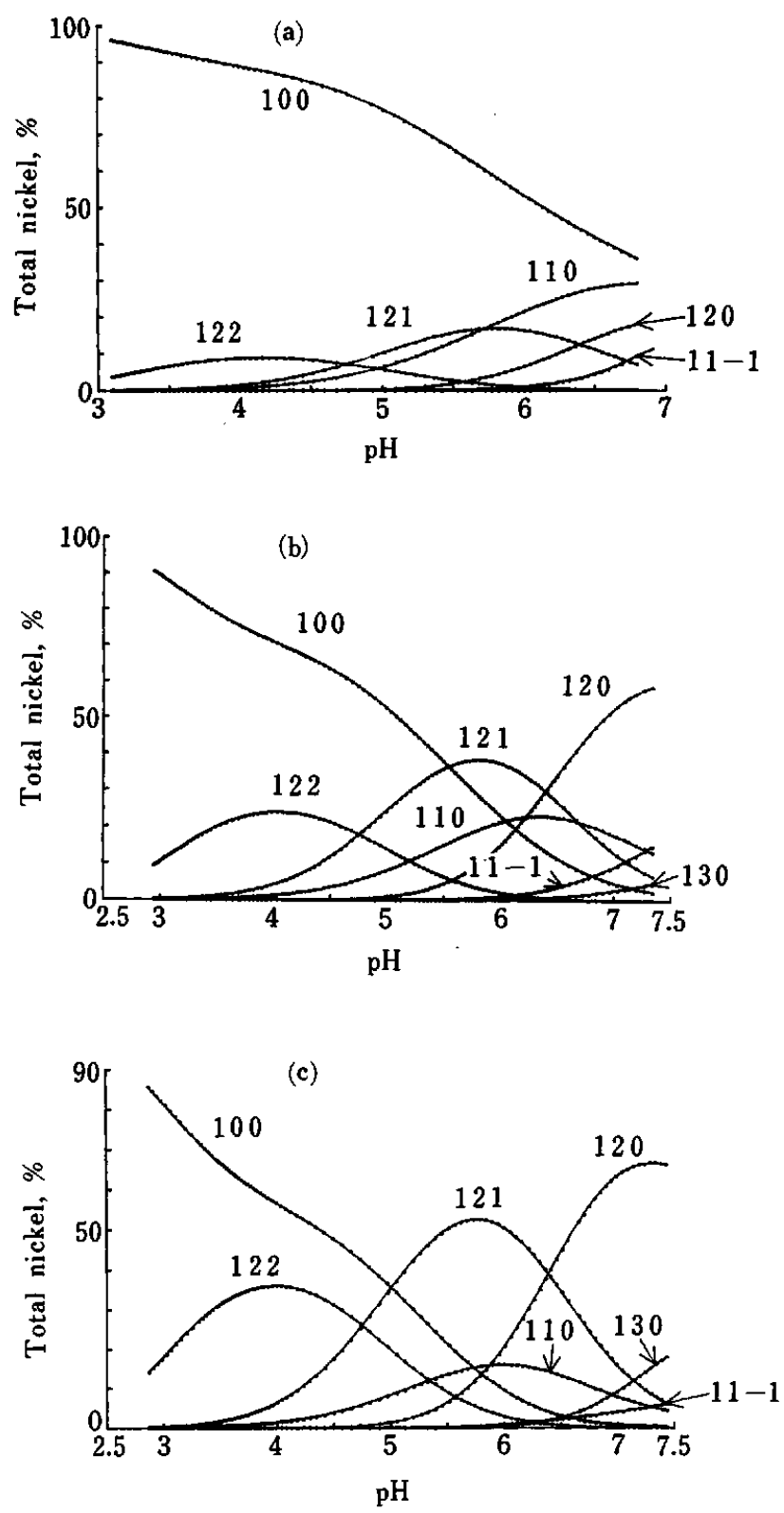

Fig. 3 Species distribution plots for $1: 1,1: 2$ and $1: 3 \mathrm{mix}$ tures of nickel(II) with aspartame. (a) $[\mathrm{Ni}(\mathrm{II})]:[\mathrm{LH}]=1: 1$, (b) $1: 2$, (c) $1: 3$.

Fig. 3. The complex formations of $\mathrm{NiL}_{2} \mathrm{H}_{2}{ }^{2+}$ and $\mathrm{NiL}_{2} \mathrm{H}^{+}$start at low $\mathrm{pH}$ and reach maxima at $\mathrm{pH} 4.0$ and 5.7, as shown in Fig. 3(c). Increase in the ligand concentration leads to an increase in the $1: 2$ complex species. $\mathrm{NiL}_{2}$ becomes predominant at the higher $\mathrm{pH}$. $\mathrm{NiL}_{3}$ type complex is present in small amounts.

At a metal/aspartame raio of $1: 3$, the concentration of nickel(II) aqueous ion decreases to zero percentage at $\mathrm{pH}=7$.

The species distribution diagrams for cobalt(II), copper(II) and manganese(II) systems are shown in Figs. 4-6.

Formation of cobalt(II)-aspartame complexes starts at

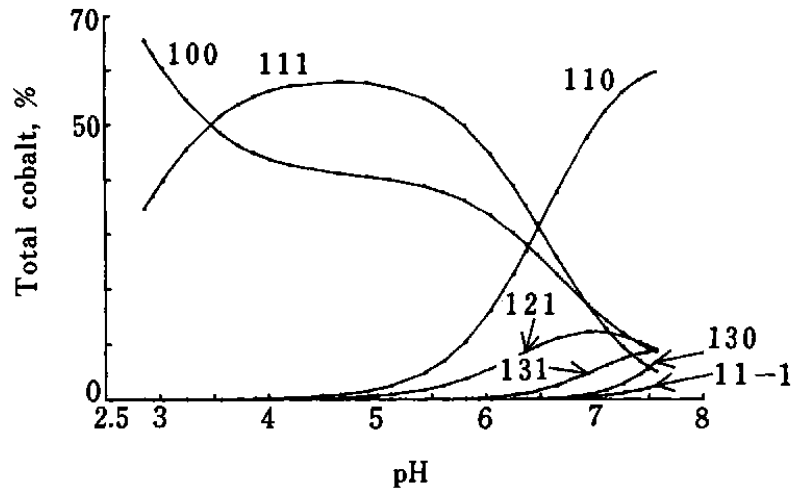

Fig. 4 Species distribution plots for 1:3 mixture of cobalt(II) with aspartame.

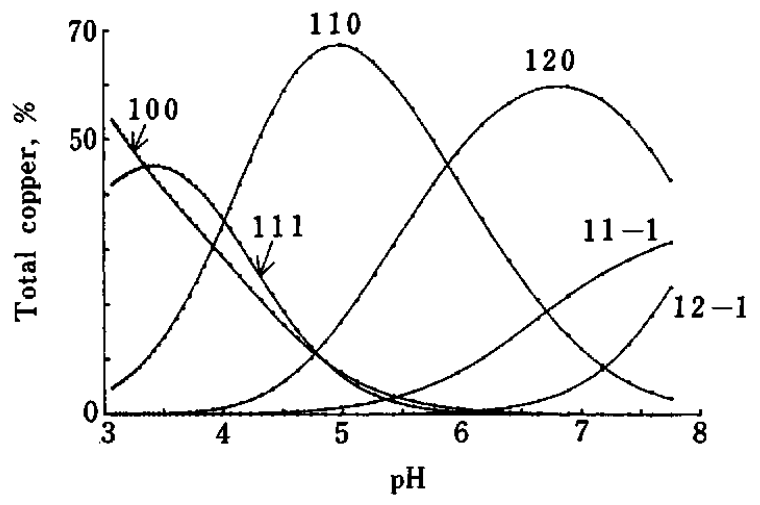

Fig. 5 Species distribution plots for 1:2 mixture of copper(II) with aspartame.

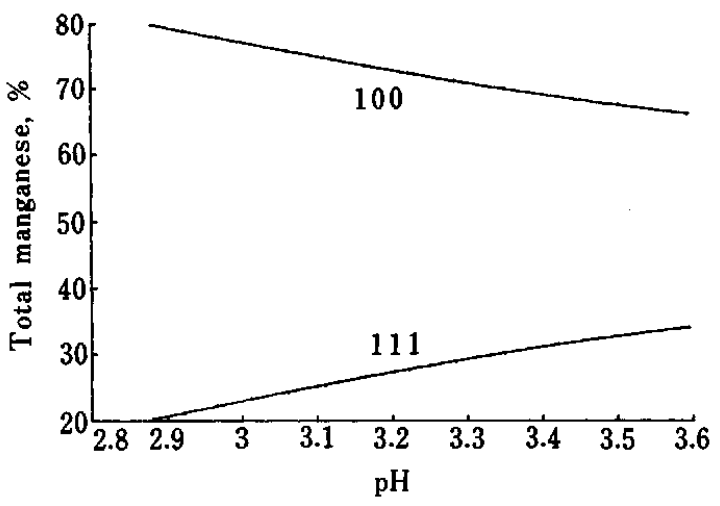

Fig. 6 Species distribution plots for 1:3 mixture of manganese(II) with aspartame.

low pH. Figure 4 demonstrates the formations of species, $\mathrm{CoLH}^{2+}, \mathrm{CoLH}_{-1}, \mathrm{CoL}_{2} \mathrm{H}^{2+}, \mathrm{CoL}_{3} \mathrm{H}^{2+}, \mathrm{CoL}_{3} \mathrm{H}^{2+}$ and $\mathrm{CoL}_{3}^{-}$and indicates the significance of $\mathrm{CoL}$ type complexes. The protonated complex $\mathrm{CuLH}^{2+}$ is important at pH 6.5. About 15 percent of the cobalt(II) ion does not form any complexes at $\mathrm{pH}=7$ at a metal/ aspartame ratio of $1: 3$. 
Figure 5 demonstrates the successive formations of the species $\mathrm{CuLH}^{2+}, \mathrm{CuL}^{+}, \mathrm{CuLH}_{-1}, \mathrm{CuL}_{2}$ and $\mathrm{CuL}_{2} \mathrm{H}_{-1}^{-}$. The major complex species at $\mathrm{pH}=4-7$ is $\mathrm{CuL}^{+}$and $\mathrm{CuL}_{2}$. At higher $\mathrm{pH}$, the $\mathrm{CuLH}_{-1}$ and $\mathrm{CuL}_{2} \mathrm{H}_{-1^{-}}$species start.

Figure 6 shows the formation of $\mathrm{MnLH}^{2+}$ species for manganese(II) system. The precipitation of $\mathrm{Mn}$ (II) occurs at lower $\mathrm{pH}$ values.

\section{Comparisons among metal complexes}

These studies suggest that stable $\mathrm{ML}^{+}$complexes occur at the $\mathrm{Co}$ (II), $\mathrm{Ni}(\mathrm{II})$, and $\mathrm{Cu}(\mathrm{II})$-systems. It is clear that the Irving-William's order: $\mathrm{Co}$ (II) $<\mathrm{Ni}$ (II) $<\mathrm{Cu}($ II) $>$ $\mathrm{Zn}(\mathrm{II})^{11}$ is satisfied for $\mathrm{ML}^{+}$complex. Nickel(II) and cobalt(II) form $1: 3$ complexes, which do not exist in the system of copper(II).

The cobalt(II) and copper(II) complexes are found to be more stable than those with glycyl-L-phenylalanine $\left(\log \beta_{110}: 2.91 \pm 0.02\right.$ for $C o(I I)$ complex, 5.26 \pm 0.01 for $\mathrm{Cu}$ (II) complex). ${ }^{15}$ It is assumed that the carboxyl group in aspartyl residue in the metal(II) complex may participate in metal(II) binding from axial position. Such contribution of the carboxyl group has been observed in the complex formation of copper(II) with Laspartyl-L-alanyl-L-histidine ${ }^{16}$ and $\mathrm{L}$-histidine. ${ }^{17}$ But the structures of the metal complexes need to be investigated by other methods (NMR, ESR etc.). Amide proton of metal(II) complexes was ionized with increasing $\mathrm{pH}$. $\mathrm{ML}^{+}$species produces a $\mathrm{MLH}_{-1}$ complex ( $\mathrm{M}=\mathrm{Co}$ (II), $\mathrm{Ni}(\mathrm{II})$, and $\mathrm{Cu}(\mathrm{II}))$. Substitution reactions of peptide protons by these metal ions occur in the metal peptide complexes. ${ }^{13}$ Other deprotonated species ( $\mathrm{ML}_{2} \mathrm{H}_{-2}, \mathrm{ML}_{3} \mathrm{H}_{-1}$ etc.) could not be found in the $\mathrm{pH}$ region of $2.8-8.0$.

\section{References}

1. L. D. Stegink and L. J. Filer Jr., “Aspartame: Physiology and Biochemistry", Marcel Dekker, Inc., New York, 1984.

2. C. Argoudelis, J. Chromatogr., 303, 256 (1984).

3. W. S. Tsang, M. A. Clarke and F. W. Parrish, J. Agric. Food Chem., 33, 734 (1985).

4. E. C. Signoretti, A. Dell'Utri and A. De Salvo, Bull. Chim. Farm., 122, 289 (1983).

5. F. Kvansnicka, J. Chromatogr., 390, 237 (1987).

6. R. H. Mazur and T. Craig, Am. Soft Drink J., 94, 1 (1971).

7. I. Furda, P. D. Malizia, M. G. Kolor and P. J. Vernieri, J. Agric. Food Chem., 23, 340 (1975).

8. M. L. D. Touche and D. R. Williams, J. Chem. Soc. Dalton Trans 1, 1976, 2001.

9. C. Gilon, R. Leshem, Y. Tapuhi and E. Grushka, J. Am. Chem. Soc., 101, 7612 (1979).

10. P. Gozel, E. Gassmann, H. Michelsen and R. N. Zare, Anal. Chem., 59, 44 (1987).

11. G. K. R. Markar, M. L. D. Touche and D. R. Wiliams, J. Chem. Soc. Dalton Trans 1, 1976, 1016.

12. D. J. Leggett, "Computational Methods for the Determination of Formation Constants", Plenum Press, New York, 1985.

13. H. Sigel and R. B. Martin, Chem. Rev., 82, 385 (1982).

14. W. S. Kittl and B. M. Rode, Inorg. Chim. Acta, 66, 103 (1982).

15. J. L. Biester and P. M. Ruoff, J. Am. Chem. Soc., 81, 6517 (1959).

16. J-P. Laussac and B. Sarkar, Biol. Chem., 25, 7563 (1980).

17. M. Itabasi and K. Itoh, Bull. Chem. Soc. Jpn., 53, 3131 (1980).

(Received May 25, 1992)

(Accepted August 17, 1992) 